\title{
MUDANÇAS INSTITUCIONAIS NA RELAÇÃO ENTRE PRODUTORES E PROCESSADORES DE LEITE: UM ESTUDO DE CASO NOS ESTADOS DE MINAS GERAIS E PARANÁ
}

\author{
Institutional Changes in the Relationship Between Producers and Milk Processors: A Case Study in \\ the States of Minas Gerais and Paraná
}

\begin{abstract}
RESUMO
O Sistema Agroindustrial do Leite brasileiro passou por mudanças institucionais entre 1990 e 2018. As Instruções Normativas referentes ao leite estabelecidas pelo governo federal entre 2002 e 2018 exigiram dos agentes novos parâmetros técnicos de produção que podem impactar a organização industrial do setor. Partindo dessa mudança institucional, este estudo pretende responder a seguinte questão: Quais os efeitos das mudanças institucionais nas relações entre produtores rurais e laticínios no SAG do leite no Brasil? O objetivo do estudo é analisar os efeitos da mudança institucional IN 62, nas especificidades dos ativos dedicados, temporal e locacional, e suas implicações na relação entre produtores e processadores de leite. O estudo valeu-se de uma abordagem qualitativa com questionários aplicados a produtores e entrevistas com processadores de duas das principais regiões produtoras de leite no Brasil. Em Ponte Nova-MG, tradicional produtora de leite, aumentaram as estratégias de fidelização com contratos formais de pagamento por qualidade e assistência técnica em função do crescimento da concorrência, decorrente das mudanças nas especificidades de ativos na relação entre produtores e processadores. Em Castro-PR, a IN 62 não alterou as relações entre produtores e processadores.
\end{abstract}

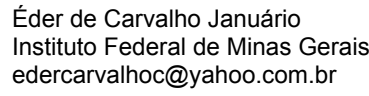

Maria Sylvia Macchione Saes Universidade de São Paulo

ssaes@usp.br

Alexandre Chibebe Nicolella Universidade de São Paulo nicolella@usp.br

Roberta de Castro Souza Pião

Universidade de São Paulo

robertacsouza@usp.br

Recebido em: 22/04/2020. Aprovado em: 15/03/2021.

Avaliado pelo sistema double blind review

Avaliador científico: Angélica da Silva Azevedo

DOI: $10.48142 / 2320211640$

\begin{abstract}
The Brazilian dairy agroindustrial system underwent institutional changes between 1990 and 2018. The Normative Instructions for milk established by the federal government between 2002 and 2018 demanded from the agents new technical parameters of production that may impact the industrial organization of the sector. Based on this institutional change, this study aimed to answer the following question: what were the effects of institutional changes on the relationships between rural producers and the milk industry in Brazil's agroindustrial system? The aim of this study is to analyze the effect of the institutional changes NI 62 on the specificities of the dedicated, temporal and locational assets, and their implications for the relationship between milk producers and processors. The study used a qualitative approach with questionnaires applied to dairy producers and interviews with the processors from two of the main producing regions of Brazil. In Ponte Nova-MG, a traditional milk producer, loyalty strategies with formal payment contracts for quality and technical assistance increased due to the growth of the competition, due to the changes in the specificity of assets in the relationships between producers and processors. In Castro-PR, the NI 62 did not change the relationship between producers and processors.
\end{abstract}

Palavras-chave: Mudança Institucional; Sistema Agroindustrial do Leite; Estruturas de Governança; Especificidade de Ativo. Keywords: Institutional changes; Dairy Agroindustrial System; Governance Structures; Asset Specificity. 


\section{INTRODUÇÃO}

O setor de lácteos ocupa uma posição de destaque entre os sistemas agroindustriais (SAGs) ${ }^{1}$. O leite fornece uma renda diária para inúmeros pequenos produtores rurais, provendo sustento regular para suas famílias. Ademais, é uma das principais fontes de proteínas para a população, possuindo enorme relevância para o desenvolvimento infantil, segundo a Organização das Nações Unidas para Alimentação e Agricultura (FAO, IFAD, UNICEF, WFP \& WHO, 2018).

Devido a essa importância, o SAG do leite tem sido objeto de políticas públicas visando tanto à manutenção da renda dos produtores quanto ao fornecimento do produto para o consumo urbano, particularmente para as regiões e famílias de baixa renda. Adicionalmente, segundo a Food and Agriculture Organization, (FAO) (2018), mudanças na dinâmica dessa cadeia a partir dos anos de 1990 têm levado a uma significativa redução do número de produtores e à forte consolidação da indústria mundial de laticínios, resultando em uma reorganização das relações entre os agentes do SAG (Rocha \& Carvalho, 2018; Gerosa \& Skoet, 2013; Kischner et al., 2019).

No Brasil, a regulamentação esteve presente em vários momentos do desenvolvimento do SAG do leite. O primeiro período ocorreu a partir do final dos anos de 1940, marcado por diferentes políticas intervencionistas, dentre as quais se destaca o controle dos preços do leite no varejo e ao produtor. O segundo período teve início no final da década de 1980, com a desregulamentação dos preços e abertura econômica. Esse momento apresentou, também, as seguintes características: a criação de políticas destinadas ao incremento do consumo de leite pela população de baixa renda, tais como o Programa Nacional do Leite (PNL) e a adoção de medidas que visavam tornar a cadeia nacional competitiva no mercado mundial, com destaque para o Programa Nacional de Melhoria da Qualidade do Leite - PNQL (Oliveira \& Silva, 2012; Brasil, 2011). Por fim, o terceiro período surgiu nos anos 2000, com a implantação da Instrução Normativa 51 (IN 51) de 2002, substituída posteriormente pela Instrução Normativa 62 (IN 62) de 2011, e em 2018, pelas IN 76 e IN 77, que definiram novos critérios para a produção de leite cru refrigerado no Brasil (Brasil, 2011; Brasil, 2018a; Brasil, 2018b).

${ }^{1}$ Define-se SAG como um conjunto de contratos cuja arquitetura responde ao alinhamento das características das transações e do ambiente Institucional (Zylbersztajn \& Farina, 1999, p. 254 ).
Em 2018, a IN 62 foi revogada sendo substituída pelas IN 76 e IN 77 que regulam a produção de leite nos elos do produtor e do processador no SAG do leite. A IN 76 trata das características e da qualidade do produto na indústria. Já a IN 77 define os critérios para obtenção de leite de qualidade e seguro ao consumidor, englobando desde a organização da propriedade, suas instalações e equipamentos, até a formação e a capacitação dos responsáveis pelas rotinas cotidianas e o controle de doenças relacionadas ao rebanho leiteiro. Além das mudanças técnicas, o novo regramento determina que os produtores passem a realizar o controle gerencial na obtenção do leite, utilizando ferramentas de gestão de qualidade nas propriedades (Brasil, 2018a; Brasil, 2018b).

Em suma, a IN 77 especifica os critérios técnicos do leite, tais como contagem bacteriana total (CBT) e contagem de células somáticas (CCS), entre outros, enquanto a IN 76 especifica critérios de adequação de ativos específicos para a operação da atividade leite na indústria. Quando se faz uma análise comparativa entre a IN 62 e a IN 76, as condições de transporte e armazenamento continuam da mesma forma como descrito na IN 62, podendo o leite ser armazenado em tanque individual ou de uso comunitário (Brasil, 2018a, Brasil, 2018b).

Além disso, no que tange aos investimentos para a operação da atividade, constata-se que as INs 76 e 77 mantiveram os mesmos ativos necessários para a produção e coordenação do SAG do leite, ou seja, ativos dedicados (tanque de resfriamento e caminhão tanque), capital humano (treinamentos) e locacional (aumentou o raio para a captação de leite) e, por fim, a especificidade temporal seguindo a mesma lógica da IN 62 (Brasil, 2018a; Brasil, 2018b; Williamson, 1991).

Observa-se, portanto, que a IN 62 trouxe mudanças importantes nos ativos necessários à produção e ela será o foco deste estudo, cujo objetivo é responder à seguinte questão: Quais foram os efeitos das mudanças institucionais nas relações entre produtores rurais e laticínios no SAG do leite no Brasil? Especificamente, pretende-se analisar as alterações na especificidade temporal e locacional de ativos dedicados que a IN 62 trouxe em seu texto e seus efeitos sobre a estrutura de governança, ou seja, na relação contratual entre produtor e processador de leite (laticínio).

Para responder à essa questão, o estudo se apoia na Nova Economia Institucional (NEI), em suas duas vertentes: a macroinstituicionalista, que foca no papel das regulamentações sobre o desempenho econômico (Farina,

Organizações Rurais \& Agroindustriais, Lavras, 23:e1640, 2021 
Azevedo \& Saes, 1997) e a microinstitucionlista (North 1990), que visa analisar as escolhas estratégicas das firmas, a partir dos condicionantes institucionais e os atributos das transações (Williamson, 1973a; 1973b). Como destaca North (1990), as instituições importam para a definição do ambiente de negócios, já que determinam os incentivos aos agentes econômicos, estabelecendo as condições em que as atividades empresariais podem (ou não) florescer. Essa visão reforça a importância da interação entre instituições e ambiente de negócios na decisão de governança adotada.

Admite-se que as alterações no ambiente empresarial provocam reflexos competitivos e influenciam diretamente as estruturas de governança. A depender da forma como a dinâmica modifica os custos de transação envolvidos nas relações entre os agentes produtivos do SAG, um novo desenho das estratégias será verificado (Muris, Scheffman, \& Spiller 1992; Williamson, 1991).

Este artigo está estruturado em cinco seções além desta introdução. A parte 2 apresenta o referencial teórico que servirá como base do estudo, no qual serão expostos os elementos conceituais que auxiliarão na compreensão dos objetivos propostos pela pesquisa. A parte 3 traz as fases da formação do ambiente institucional do leite no Brasil, exibindo as principais mudanças no setor ao longo dos anos. A parte 4 apresenta os resultados das pesquisas com os produtores com e sem tecnologia como uma proxy das consequências do atendimento da regulamentação. Para observar in loco as mudanças das relações contratuais entre os produtores de leite e os laticínios, a parte 5 apresenta duas experiências - uma em Minas Gerais, na região tradicional produtora de leite - Ponte Nova-, e no Paraná, em Castro, região considerada como a que apresenta, no Brasil, a melhor tecnologia na produção leiteira (IBGE, 2015). Finalmente é apresentada a discussão dos resultados a partir das proposições elaboradas no final da seção de fundamentação teórica. Em seguida, são apresentadas algumas considerações finais e implicações para estudos futuros.

\section{FUNDAMENTAÇÃO TEÓRICA}

A Nova Economia Institucional (NEI), em sua visão macro, tem como principal autor Douglass North (1990). Conforme a definição de North, o ambiente institucional compreende as regras políticas, econômicas, sociais e legais que orientam os agentes em suas transações. Adentrando nessa abordagem, são analisadas as regras formais (ex.: políticas e regulamentação) e as regras informais (ex.: valores culturais e códigos de ética).
Sendo assim, para North (1990), as instituições (formais e informais) são fundamentais na estruturação da interação social, econômica e política. No trabalho em questão, essa abordagem permitirá verificar o impacto das mudanças das instituições nas estratégias das organizações. No ramo micro da NEI, a Economia dos Custos de Transação (ECT) tem como foco a Estrutura de Governança. Essa corrente está enraizada no trabalho de Ronald Coase The Nature of the Firm (Coase 1937), posteriormente desenvolvido por Klein, Crawford \& Alchian (2012); e Williamson (1987,1991). A ECT pode ser vista como uma extensão do paradigma da Moderna Organização Industrial que, enriquecida e complementada com a visão do ambiente institucional e das variáveis transacionais, caracteriza a organização das firmas e dos mercados (Joskow, 1995; Mondelli \& Zylbersztajn, 2008). A ECT argumenta que os custos de transação são custos de trocar, capturar e proteger direitos de propriedade e ocorrem devido às necessidades de: (a) elaborar e negociar os contratos; (b) mensurar e fiscalizar direitos de propriedade; (c) monitorar o desempenho; (d) organizar atividades; (e) adaptar às mudanças no sistema econômico; (f) monitorar as transações; e (g) monitorar o desempenho dos agentes envolvidos (Milgrom \& Roberts, 1992).

A importância dos custos de transação é enfatizada quando constatamos que, na sua ausência, não haveria o problema de criação e proteção de valor. Qualquer estrutura de governança das transações (mercado, contratos ou hierarquia) seria equivalentemente apropriada, isto é, conduziria à maximização do valor. A ação estratégica seria trivial. Quando custos de transação são introduzidos (isto é, há falhas de mercado), os direitos de propriedade não são perfeitamente protegidos. Sua proteção se torna uma atividade custosa, sendo que recursos serão gastos para apropriar direitos de propriedades. Portanto, valores são dissipados.

De acordo com Williamson (1973a, 1985), a existência de custos de transação se fundamenta nos pressupostos comportamentais do modelo, quais sejam: racionalidade limitada e oportunismo. A racionalidade limitada indica que os indivíduos são racionais, buscam a maximização da satisfação e dos lucros, porém são limitados por problemas informacionais. Isso significa que, em vez de uma decisão ótima, o agente adota a melhor decisão possível, dado o seu conhecimento limitado. Por oportunismo, se entende que os agentes econômicos agem em benefício próprio (autointeressados) com astúcia.

Uma informação incompleta ou limitada pode dar margem a ações oportunistas: os agentes podem utilizar 
informações privilegiadas em benefício próprio ou a não previsão de todas as eventualidades pode resultar em mudanças que possibilitem ganhos decorrentes de ação oportunista. Isso cria o potencial de hold-up ${ }^{2}$, que é o principal determinante da adoção de estruturas híbridas visando a reduzir dissipação de valor (Klein, Crawford, \& Alchian 2012; Williamson, 1985).

Williamson (1985) identifica três atributos das transações que servem de orientação para a tomada de decisão com relação à estrutura de governança: (a) Frequência das transações: quanto maior essa frequência, menores os custos fixos médios associados à coleta de informações e à elaboração de contratos, assim como maior a facilidade de se impor perdas aos contratantes para evitar comportamento oportunista; (b) Incerteza: quanto maior a incerteza, mais complexo torna-se o desenvolvimento de parcerias de longo prazo e maior a possibilidade de desentendimentos na recontratação. A incerteza surge das mudanças no ambiente econômico e nas preferências dos consumidores, bem como da complexidade do próprio ambiente econômico que impossibilita uma avaliação precisa; (c) Especificidade de ativos: a especificidade do ativo significa que uma firma à jusante ou à montante realizou investimentos inerentes à atividade da transação. Nessa lógica, o valor de troca é mais elevado quando a transação ocorre entre essas duas firmas que investiram na relação Perry (1989).

O atributo especificidade é considerado como o mais decisivo na definição das estruturas de governança. Quanto maior a especificidade do ativo, maior é a perda associada a uma ação oportunista por parte de outro agente. Se os ativos não são específicos, as transações entre os agentes podem ocorrer via mercado. Com o aumento do nível de especificidade, os custos de transação aumentam, tornando ineficiente a estrutura de governança via mercado. A integração vertical será mais vantajosa sob a forma de mercado, à medida que os níveis de especificidade do ativo se elevam. A literatura define seis principais categorias de ativos específicos: física, locacional, temporal, humanas, de marca e dedicada Williamson (1991).

A principal contribuição da ECT é a incorporação da coordenação na análise do desempenho (e competitividade) das firmas. Quanto mais adequada

2Uma situação de hold-up ocorre quando uma das partes em uma relação contratual força a renegociação visando apropriar-se das quase rendas decorrentes dos investimentos específicos realizados pela contraparte, o que é possível em razão de o contrato que governa o relacionamento ser incompleto (Klein, 2000, p. 124). for a coordenação entre fornecedores e clientes minimizando os custos de transação -, maior será a adaptação às mudanças de ambiente, menores serão os conflitos das relações cliente/fornecedor e maior a captura de valor. Ademais, a coordenação está diretamente ligada aos condicionantes macroinstitucionais, já que mudanças no ambiente regulatório podem alterar características dos atributos das transações, refletindo em novas configurações de governança, como apontado a seguir.

Tendo como referencial a NEI, foi elaborado um mapa conceitual com duas proposições para analisar o efeito da mudança institucional (IN 62) sobre as estruturas de governança entre os laticínios e os produtores rurais do SAG do leite. Esse mapa é apresentado na Figura 1.

Como se pode notar, de um lado a proposição 1 pressupõe que a queda da especificidade dos ativos leva a formas mais tênues de relacionamento entre os laticínios e os produtores. De outro, ao verificar o aumento do mercado relevante e crescimento da concorrência entre laticínios, é esperado que estes construam laços mais fortes com os produtores (estruturas de governança mais fortes) visando manter a participação de mercado.

\section{PROCEDIMENTOS METODOLÓGICOS}

Atendendo ao objetivo geral do artigo e às proposições apresentadas, esta pesquisa utiliza-se da abordagem qualitativa, focada em estudo de caso múltiplo relacionado ao SAG do leite no Brasil visando compreender as implicações da regulamentação nas transações entre produtores e processadores sobre as lentes teóricas da NEI.

Observa-se que para esta pesquisa os estudos de caso são recomendados, considerando que a natureza da pesquisa está ligada a fenômenos contemporâneos dentro do contexto da vida real (Yin, 2014). Adicionalmente, conforme destaca Gil (2019), os estudos de caso podem ser úteis na investigação da estrutura de uma indústria, visando identificar fatores que influenciam as mudanças estruturais de um dado setor. Este estudo segue essa lógica, visando coletar indícios sobre fenômenos ocorridos na indústria leiteira com a implementação das regulamentações de qualidade do leite.

Neste estudo foram utilizados dois tipos de instrumentos. O primeiro foi a aplicação de questionários com produtores rurais. Essa escolha ocorreu pela característica desse instrumento de pesquisa, que permite

Organizações Rurais \& Agroindustriais, Lavras, 23:e1640, 2021 
atingir um número significativo de respostas, garantido maior anonimato (Gil, 2019). O segundo instrumento foi a realização de entrevistas semiestruturadas com os gestores dos laticínios das regiões, aos quais os produtores entrevistados (na primeira etapa) estavam vinculados. Nesse caso, se optou pelas entrevistas, pois permitem o aprofundamento das informações obtidas via questionários (Gil, 2019).

Com relação à primeira etapa, aplicação de questionários aos produtores, o processo de amostragem utilizado é não probabilístico, pois se parte de um universo naturalmente restrito, em que a escolha dos respondentes que fizeram parte da amostra ocorreu por conveniência ou acessibilidade dos pesquisadores (Barbetta, 2003; Gil, 2019). A literatura aponta que essa escolha pode gerar algumas limitações de inferência para o setor como um todo, mas não invalida os resultados da pesquisa, já que o objetivo é observar e caracterizar as mudanças nas relações entre os produtores e os laticínios (Barbetta, 2003). Foram aplicados 321 questionários aos produtores do SAG do leite que utilizam diferentes tecnologias em seu processo produtivo, e produzem em duas regiões do Brasil: Minas Gerais e Paraná, no ano de 2015. Cumpre ressaltar que as indicações dos entrevistados partiram dos laticínios, associações e dos próprios produtores, que recomendaram propriedades de diversos tamanhos e níveis de tecnologia.

Nos questionários aos produtores foram levantadas presencialmente, por meio de questões objetivas, informações sobre as características do proprietário, atividade, propriedade, mão-de-obra, uso de tecnologia e qualidade do produto em dois períodos distintos, $2008 \mathrm{e}$ 2015. Essa fase teve como objetivo descrever a mudança que potencialmente pode ter ocorrido devido a IN 62, a qual foi implementada no final de 2011.

Os questionários foram tabulados em planilhas eletrônicas (Excel) onde cada produtor teve suas características descritas nas colunas $X_{i}$ em dois períodos do tempo, $t$ e $t+7$. Assim, para uma mesma característica $X$ observa-se o indivíduo $i$ em dois períodos, $X_{i t}$ e $X_{i t+7}$. Dessa forma, baseando-se em análises descritivas e tabelas cruzadas, foi possível estimar proporções, médias, variâncias e desvios das principais características para os dois períodos de tempo.

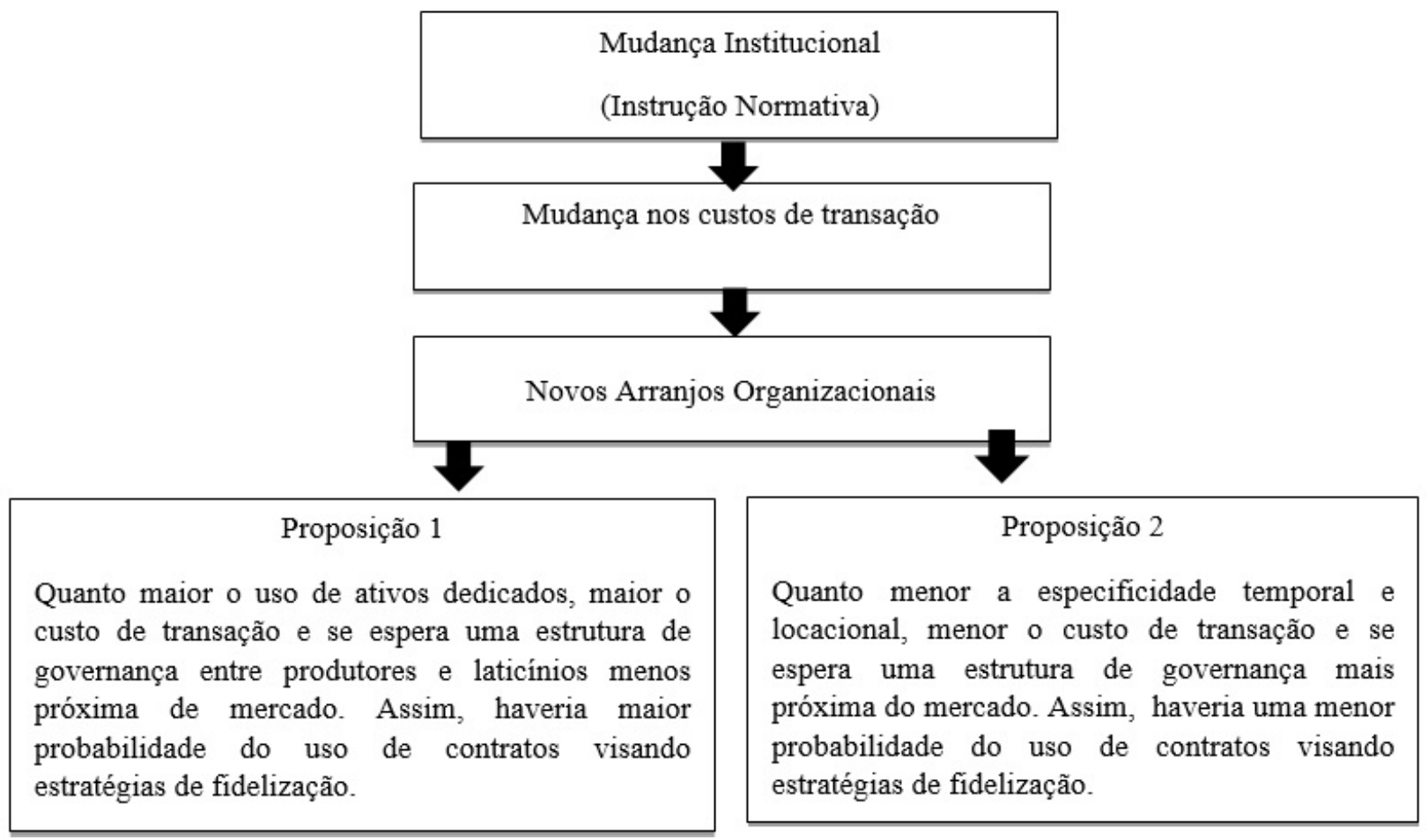

FIGURA 1 - Esquema conceitual das mudanças nas estruturas de governança

Fonte: Elaborado pelos autores 
Com relação à segunda etapa, foram realizadas duas entrevistas em laticínios, uma na cidade de Ponte Nova-MG e a outra na cidade de Castro-PR. Em cada laticínio foi entrevistado o profissional responsável pela captação do leite ou aquele envolvido na gestão da qualidade do leite e assistência ao produtor na adequação aos parâmetros exigidos pela Instrução Normativa. A entrevista buscou investigar as mudanças ocorridas na relação comercial entre produtor e laticínio após a implementação da IN 62. É importante frisar que a escolha dessa IN se deve ao seu grande impacto na característica do produto negociado -leite-, mudando a especificidade locacional do ativo, entre outras, conforme já relatado anteriormente.

A escolha dos laticínios se deu devido à representatividade dos laticínios na captação de leite no Brasil. Observa-se que Minas Gerais é o principal produtor de leite do Brasil, responsável por $26,4 \%$ da produção nacional, ou seja, 8,9 bilhões de litros de leite. Metade dos dez maiores municípios produtores de leite estão localizados nesse estado (IBGE, 2018). Com relação ao Paraná, este estado é responsável por uma produção 3,9 bilhões de litros, o que representa $12,3 \%$ da produção nacional com duas importantes áreas de produção de leite: a cidade de Castro, que liderou o ranking da produção nacional, com $0,9 \%$ de participação no Brasil e respondendo por $6,7 \%$ da produção do estado. De acordo com o (IBGE, 2018), Castro é a cidade com maior produção e produtividade de leite do Brasil.

As entrevistas foram semiestruturadas e compostas por 25 questões dissertativas sobre a produção do laticínio, forma de obtenção e característica do insumo, forma de escolha de produtores e tipo de estrutura de governança utilizada, bem como questões sobre ambiguidades, complexidades e posicionamento estratégico. A análise foi realizada seguindo as três etapas propostas por Miles, Huberman, \& Saldana (2014): redução/codificação, apresentação, conclusões. A codificação se baseou-se em três códigos predefinidos (extraídos da revisão de literatura): estruturas de governança, especificidade de ativos, ambiente institucional (instrução normativa), além daqueles que emergiram durante a análise, indutivamente. Chegou-se à conclusão da utilização das três diferentes categorias de estruturas de governança as quais, assim como mostra a literatura, variam entre condições da transformação do mercado competitivo pelo aumento da especificidade do ativo.
As atividades de codificação e de interpretação constituem um processo de criação de sentidos (sensemaking), tal sentido dependendo da reflexividade do pesquisador e de sua capacidade de teorização (Mesquita, Pozzebon \& Petrini 2020). A intensidade de uma pesquisa, sobretudo a que inclui observação participante e técnicas de inspiração etnográfica, aumenta a possibilidade de gerar uma compreensão profunda e plausível de um fenômeno social que se deseja investigar. A análise e a discussão dos resultados a seguir estão baseadas nesses resultados encontrados em campo. Por fim, foi utilizado o software Transcriber nas transcrições das entrevistas.

\section{RESULTADOS}

\subsection{Produtores de leite}

As informações das entrevistas estão apresentadas nas Tabelas 1 e 2. A Tabela 1 contém as características dos produtores, de acordo com o uso da ordenha mecânica versus a manual na produção de leite. Como pode ser observado, de 2008 a 2015 houve um aumento no número de produtores que usam a ordenha mecânica, sendo que $63 \%$ tinham ordenha em 2008 e esse número subiu para $79 \%$ em 2015. Provavelmente esse aumento foi induzido não somente pela regulamentação, mas também pelas políticas de incentivo para a compra de tais equipamentos (Reis, 2007). Esses produtores têm produtividade mais elevada. No ano de 2015 os produtores sem ordenha apresentavam produtividade de 12 litros por vaca/dia e aqueles com ordenha apresentavam produtividade de quase 21 litros vaca/dia. Inclusive, é importante destacar que os produtores com ordenha se mostram mais consistentes na produtividade, com um desvio padrão mais baixo do que aqueles que não o utilizam.

$\mathrm{O}$ ano de 2015 igualmente registrou um aumento do número de produtores que utilizaram a ordenha mecânica e obtiveram prêmio de qualidade: enquanto $47 \%$ dos que não utilizavam ordenha mecânica receberam prêmio, dentre os que a utilizavam $64 \%$ receberam prêmio. As informações relevantes sobre a qualidade do leite referem-se ao número de contagens de células somáticas e bacterianas. Os dados relatados apresentam desvio padrão elevado, mostrando grande disparidade de valores e/ou falta de precisão nas informações apresentadas. De qualquer forma, observa-se que o uso de ordenha mecânica pode refletir a dificuldade em lidar com a tecnologia, a qual exige maior cuidado na limpeza do equipamento após o uso. 
TABELA 1 - Características dos produtores de acordo com a utilização ou não da ordenha mecânica (em 2008 e 2015)

\begin{tabular}{ccccc}
\hline Variáveis & \multicolumn{2}{c}{ Sem ordenha mecânica } & \multicolumn{2}{c}{ Com ordenha mecânica } \\
\cline { 2 - 5 } & 2008 & 2015 & 2008 & 2015 \\
\hline Número de produtores & 116 & 65 & 205 & 248 \\
Produtividade (média 1/vaca/dia) & 11,05 & 12,04 & 17,04 & 20,77 \\
Desvio Padrão & $\mathbf{( 1 0 , 6 1 )}$ & $\mathbf{( 1 2 , 6 8 )}$ & $\mathbf{( 8 , 7 7 )}$ & $\mathbf{( 8 , 3 6 )}$ \\
Premiado produtores (número) & 25 & 27 & 98 & 160 \\
Produtor premiado (\%) & $21,6 \%$ & $41,5 \%$ & $47,8 \%$ & $64,5 \%$ \\
Células Somáticas (CS/ml) & 435.455 & 252.167 & 412.183 & 354.781 \\
Desvio Padrão & $\mathbf{( 2 1 5 . 7 9 5 )}$ & $\mathbf{( 9 0 . 7 4 0 )}$ & $\mathbf{( 2 2 3 . 3 2 3 )}$ & $\mathbf{( 2 0 1 . 6 6 2 )}$ \\
Contagem bacteriana & 189937,50 & 49.448 .57 & 80628,47 & 71374,94 \\
Desvio Padrão & $\mathbf{( 3 3 7 . 4 3 2 )}$ & $\mathbf{( 4 9 . 1 8 5 )}$ & $\mathbf{( 1 4 0 . 2 2 5})$ & $\mathbf{( 1 3 4 . 7 3 3 )}$ \\
Desvio Padrão & 159,96 & 156,63 & 731,7 & 802,7 \\
Litros de leite estação (média diária) & $\mathbf{( 1 7 6 )}$ & $\mathbf{( 2 0 7 )}$ & $\mathbf{( 1 . 1 8 4 )}$ & $\mathbf{( 1 . 2 1 3 )}$ \\
Litros de leite-época baixa (média diária) & 125,46 & 119,23 & 667,24 & 748,4
\end{tabular}

Nota: Total da amostra $=321$ produtores do leite

Fonte: pesquisa de campo

TABELA 2 - Características dos produtores de acordo com a utilização ou não de tanques de resfriamento (em 2008 e 2015)

\begin{tabular}{ccccc}
\hline Variáveis & \multicolumn{2}{c}{ Sem tanque de resfriamento } & \multicolumn{2}{c}{ Com tanque de resfriamento } \\
\cline { 2 - 5 } & 2008 & 2015 & 2008 & 2015 \\
\hline Produtores (número) & 132 & 75 & 189 & 246 \\
Produtividade (média litros/vaca/dia) & 12,82 & 13,76 & 16,68 & 17,20 \\
Desvio Padrão & $(13,10)$ & $(12,15)$ & $(7,10)$ & $(8,53)$ \\
Prêmio recebido (no de produtores) & 4 & 22 & 103 & 165 \\
Prêmio recebido (\%) & $3,0 \%$ & $29,3 \%$ & $54,5 \%$ & $37,1 \%$ \\
Células Somáticas (CS / ml) & 538.789 & 368.125 & 388.561 & $(202.636)$ \\
Desvio Padrão & $(278.586)$ & $(172.927)$ & $(200.192)$ & 69.310 \\
Contagem bacteriana & 168.899 & 79.052 & 77.758 & $(138.888)$ \\
Desvio Padrão & $(292.182)$ & $(62.471)$ & $(139.434)$ & 37 \\
Distância (Km) & 25 & 20 & 35 & 3,66 \\
Frequência de transporte (dias) & 3,48 & 3,04 & 3,57 & 560,70 \\
Custo mensal de energia (R\$) * & 129,07 & 215,98 & 402,13 & $(716)$ \\
Desvio Padrão & $(109)$ & $(160)$ & $(484)$ & 809,06 \\
Litros de leite estação (média diária) & 191,6 & 225,4 & 766,17 & $(1233)$ \\
Desvio Padrão & $(264)$ & $(336)$ & $(1221)$ & 753,83 \\
Litros de leite época baixa (média diária) & 157.75 & 188,7 & 699,07 & $(1.248)$ \\
Desvio Padrão & $(210)$ & $(275)$ & $(1.197)$ & \\
\hline
\end{tabular}

* Notas: Valores nominais

Total da amostra $=321$ produtores do leite

Fonte: pesquisa de campo 
Os dados da Tabela 1 também indicam escala de produção crescente para os produtores mais tecnificados - média da produção diária de leite (na safra e na estação de seca) em linha com os valores do (IBGE, 2013), que mostram uma concentração de propriedades mecanizadas. Para os produtores com ordenha a produção entre estação e baixa aumentou em média 10,5\% entre 2008 e 2015 e, para os produtores sem ordenha, a produção caiu 3,5\%. Parte desse fenômeno pode ser atribuída às exigências de regulamentações que, ao determinarem o uso da tecnologia, induzem a um aumento da escala, visando à redução de custos.

A Tabela 2 mostra as características dos produtores de acordo com o uso de tanques de resfriamento ou não. $\mathrm{O}$ número de agricultores que começaram a utilizar esses tanques aumentou de 2008 para 2015, sendo que 58\% dos produtores utilizavam o tanque em 2008 e 76\% em 2015.

Observa-se, também, que houve um aumento no número de produtores que receberam prêmios de qualidade, principalmente aqueles que possuíam tanque. Em 2015, 29\% dos produtores que não tinham tanque receberam prêmio e $67 \%$ dos que possuíam tanque receberam prêmio, sendo que um percentual bem menor ocorreu em 2008. Observa-se que o número de células somáticas em produtores sem o tanque de resfriamento em 2015 era de 368.125 Células Somáticas por mililitro (CS/ $\mathrm{ml})$. Já produtores que o utilizavam passou para 348.858 $\mathrm{CS} / \mathrm{ml}$. Considerando ainda o ano de 2015, a contagem bacteriana também é maior nos produtores sem tanques de resfriamento $(79.052 \mathrm{CB} / \mathrm{ml})$ em relação aos produtores com tanque $(69.310 \mathrm{CB} / \mathrm{ml})$. Esses resultados indicam o efeito positivo do resfriamento do leite na fazenda, em termos de qualidade melhorada.

Outro ponto que podemos observar na Tabela 2 é que a utilização do tanque de resfriamento possibilitou que a logística das empresas captasse o leite um menor número de vezes na semana devido às melhores condições de armazenamento. Se em 2015, entre os produtores sem tanque, a coleta ocorria a cada 3 dias aproximadamente, entre os com tanque de resfriamento acontecia a cada 3,66 dias. Portanto, esse fato aumentou a especificidade temporal, e possibilitou que a logística da empresa aumentasse a área de captação, conforme demonstrado na Tabela 2 .

Esse aumento na distância da captação também se deve ao fato de os laticínios investirem em caminhões de transporte refrigerados e tanques na armazenagem. Portanto, produtores com tanque possibilitam um menor número de coletas por semana e permitem que o laticínio colete a distâncias mais longas; no caso, com distância
75\% maiores (considerando 2015), como se pode observar na Tabela 2.

Também se verifica nessa tabela um aumento da produção de leite entre 2008 e 2015, tanto para os produtores com tanque como para os sem tanque, ou seja, os produtores apresentam maior escala de produção, conforme já apontado anteriormente.

Há indicações de que houve um aumento da qualidade e eficiência do leite no processo produtivo. As implicações exigidas pela instrução normativa e a melhoria da competividade do setor aceleraram o processo de concentração industrial e o aumento da produtividade, forçando os laticínios a desenvolverem estratégias na captação de leite.

\subsection{Estudo de Caso: Análise das Estruturas de Governanças}

As entrevistas para realização dos estudos de casos foram realizadas no ano de 2015 nas sedes dos laticínios. Foram entrevistados os profissionais responsáveis pela captação do leite (diretores de captação, analistas de captação de leite, e técnicos agrícolas), em geral, profissionais envolvidos na gestão da qualidade do leite e assistência ao produtor na adequação aos parâmetros exigidos pela IN 62 .

\subsubsection{A experiência do Laticínio Porto Alegre}

A primeira experiência a ser relatada é a do Laticínio Porto Alegre, situado na cidade de Ponte Nova, em Minas Gerais.

É oportuno caracterizar a região, para uma adequada compreensão do entorno: a bacia leiteira da região de Zona da Mata de Ponte Nova, MG, é composta por produtores de pequeno, médio e grande porte. $\mathrm{Na}$ região de captação do laticínio, os grandes produtores respondem por $20 \%$ da captação do leite do laticínio, enquanto os de pequeno porte respondem a $80 \%$. Para o laticínio, a tecnologia usada na captação não é um fator importante; o que importa é a sanidade no momento do ordenha e a forma de armazenamento do leite.

Uma caraterística dos grandes produtores é a capacidade de formação de opinião entre os pequenos. Este fato faz com que os grandes produtores tenham uma atenção ainda mais direcionada por parte do laticínio. Para a empresa, o requisito principal é a densidade de leite por quilômetro rodado (volume e distância). A frota de caminhões adaptados é do próprio laticínio, que oferece a coleta gratuita para os produtores fidelizados (contratos relacionais). 
Para a produção de lácteos é necessária uma qualidade diferenciada de leite para cada produto. Um exemplo é o leite UHT, para o qual a empresa exige dos produtores um número baixo de contagem de células somáticas (CCS) e de contagem bacteriana total (CBT). Como a qualidade do leite entregue é um importante fator na elaboração dos produtos, ela tende a influenciar a precificação feita pelo laticínio. Esses parâmetros advêm da IN 62.

Para que haja uma coleta eficiente, os funcionários e produtores seguem rigorosamente as especificações da IN 62: todo o leite ordenhado deve ser acondicionado em tanques de resfriamento e ser transportado para o laticínio, de dois em dois dias. Antes do acondicionamento é retirada uma amostra para as análises físico-químicas. Havendo necessidade, são feitas análises mais detalhadas no laboratório do próprio laticínio, além de outros testes mais específicos que são exigidos para determinar a qualidade do produto. A qualidade do leite é facilmente detectável por meio de testes específicos e as amostras coletadas são analisadas no laboratório do laticínio e em laboratório credenciado pelo Ministério da Agricultura Pecuária e Abastecimento - MAPA, conforme estabelecido pela IN62.

A empresa atende o produtor que consegue fornecer uma quantidade de 50 litros por quilômetros rodados; caso não tenha mais fornecedores na mesma região, outra condição exigida pela empresa é a logística de acesso, quando são avaliadas as condições das estradas e a qualidade do leite, aspectos importantes que interferem na decisão de captação do leite. A empresa também analisa o histórico dos produtores; caso já tenham fornecido leite no passado e, se por algum motivo negativo deixaram de fornecê-lo, são analisados os motivos de sua saída. A empresa não possui nenhum selo de qualidade, somente atende às regulamentações estabelecidas pela IN 62 .

Há cerca de 30 laticínios que concorrem diretamente com a empresa, destacando-se a presença de duas importantes competidoras: a cooperativa central Itambé e a BR Foods. Ambas são consideradas as maiores captadoras de leite no Brasil. A empresa tem como estratégia a diferenciação do produto pautada na qualidade e sabor caseiro.

\subsubsection{Motivações para escolhas das estruturas de governança}

Devido às mudanças institucionais houve um aumento nos custos de transação, tanto para os produtores como para o processador. Além disso, houve a diminuição do ativo locacional e da coleta a granel, aumentando do mercado relevante. Tal mudança não foi positiva para o processador, pois aumentou a disputa na região pela matéria-prima, beneficiando o produtor.

Com base nas entrevistas realizadas com os profissionais responsáveis pela captação do leite ou aquele envolvido na gestão da qualidade do leite e assistência ao produtor, constata-se que o laticínio teve que adequar suas estratégias na contratação e captação de leite cru resfriado. A empresa Laticínios Porto Alegre apresenta integração vertical, contrato $\operatorname{spot}^{3}$ e contratos relacionais. Nos casos investigados, foi comprovado que a mudança institucional alterou o ambiente de negócios no SAG do leite. Em Ponte Nova, foi identificado que a normativa diminuiu a especificidade locacional quando passa a exigir o resfriamento do leite na fazenda. Sendo assim, a distância de captação cresceu, passando de uma média de $20 \mathrm{~km}$ de distância para quase $200 \mathrm{~km}$. Essa quilometragem está alinhada com o volume do leite a ser coletado.

Com a expansão da distância de captação, observou-se também o aumento do mercado relevante, surgindo oportunidades para os laticínios concorrentes atuarem nesse mercado com estratégias para disputar o leite dos produtores do laticínio Porto Alegre. É válido lembrar que a forma de governança entre os agentes era apenas o contrato relacional, sem nenhuma troca de assessoria por parte do laticínio; aproximava-se bastante do spot: o produtor podia vender para outros, mas como no passado a concorrência era menor, não havia a necessidade de mudar a governança.

Nos anos 2015, o laticínio deteve duas formas: contrato relacional, no qual existe uma relação de confiança e dependência mútua entre os agentes com obrigação de fornecimento anual em troca de ativos para manutenção da transação; e o mercado spot, onde não há nenhum contrato e o produtor tem o livre arbítrio para entregar o leite para outros fornecedores.

Para garantir o fornecimento e frear as estratégias da concorrência, foi necessário que o laticínio Porto Alegre desenvolvesse novas estruturas de governança, as quais estão expostas na Tabela 3.

Entende-se que esses fatores que explicariam a estratégia do laticínio em prol da escolha mista de governança se justificam pela heterogeneidade da qualidade do leite, aumento da concorrência e pelo mercado relevante.

${ }^{3}$ De acordo com Azevedo (1997, p. 56), "a palavra spot - ponto, em inglês - na economia, é utilizada para qualificar um tipo de mercado cujas transações se resolvem em um único instante no tempo". O mercado spot é considerado esporádico, e mesmo que a transação se repita não há obrigatoriedade de nova transação no futuro 
TABELA 3 - Mecanismos de Governança adotados pelos Laticínios Porto Alegre / Captação de Leite

\begin{tabular}{cc}
\hline $\begin{array}{c}\text { Participação de cada Estrutura de } \\
\text { Governança }\end{array}$ & Porcentagem \\
\hline $\begin{array}{c}\text { Mercado Spot } \\
\text { Contratos relacionais com obrigatoriedade de } \\
\text { entrega }\end{array}$ & 44,44 \\
Integração Vertical & 54,07 \\
\hline
\end{tabular}

Fonte: Dados da Pesquisa (2015)

Especificamente, há indicações de que a estratégia de diferenciação (dos produtos) configura-se como um elemento que ensejaria, idealmente, um maior controle hierárquico do processo produtivo. Se a marca se configura como um ativo específico, é plausível entender a maior busca por controle. Nada obstante, a escala de produção/crescimento da firma, as características do produto (sazonalidade, perecibilidade), a dispersão dos fornecedores no espaço geográfico e o poder de barganha dos grandes produtores podem introduzir desafios adicionais no que diz respeito ao controle e à própria coordenação da produção.

Diante dessa realidade, a Laticínios Porto Alegre optou por atuar tanto no mercado spot (captação de leite com os fornecedores, sem a exigência de exclusividade) quanto com contratos relacionais (captação de leite junto a fornecedores com exigência de exclusividade). Além disso, a necessidade de um relacionamento mais estreito com os fornecedores (contratos relacionais) justifica a existência de benefícios adicionais a esses fornecedores, como adiantamento de recursos financeiros oriundos de Programas do Governo Federal para o fortalecimento da agricultura familiar (PRONAF), fornecimento de ração para os animais e aquisição de tanques de resfriamento para os produtores.

\subsubsection{A experiência da Cooperativa Castrolanda}

A segunda experiência relatada foi na Cooperativa Agropecuária Castrolanda, localizada no município de Castro no estado do Paraná, na região denominada Campos Gerais. Nessa localidade, está concentrada a bacia leiteira denominada ABC, composta pelas cooperativas de Arapoti (Capal), Batavo e Castrolanda).

Conforme já apresentado, o estado do Paraná está inserido na lista dos maiores produtores de leite do Brasil, responsável por $12,3 \%$, da produção nacional e, quando comparado com os demais estados produtores, esse estado vem se destacando pela produtividade de seu rebanho leiteiro (IBGE, 2018). Com cerca de 1.616 .000 cabeças de vaca, conta com pouco mais de 100 mil produtores de leite e 370 laticínios com sistemas de inspeção federal, estadual e municipal distribuídos nos 399 municípios do estado (Defante et al. 2019).

Dentre as demais bacias leiteiras do Paraná, a cidade de Castro destaca-se pela produtividade de seus pecuaristas. Foi nessa região que, em 1951, imigrantes holandeses instalaram-se com forte conhecimento na produção de leite trazido da sua região de origem. Esses imigrantes têm o seu foco em produtividade e na qualidade da produção de leite, seguindo padrões internacionais de produção. O diferencial competitivo da região é reconhecido pelo modelo de cooperação que gera valor aos agentes do SAG do leite. Os associados administram as atividades agropecuárias de forma profissionalizada, sempre investindo em tecnologia e gestão, objetivando a melhoria da produtividade de seu rebanho. Os cooperados seguem o perfil de agricultores familiares com estrutura profissionalizada.

O potencial fornecedor de leite para a cooperativa Castrolanda passa por análise nas quais os critérios de decisão e adesão do novo produtor estão sempre focados na qualidade do leite e na produtividade. São analisados variáveis como: distância (até $149 \mathrm{~km}$ da planta processadora), padrões de sanidade (controle de doenças do rebanho e boas práticas na ordenha), padrões de qualidade (CCS, CBT, teor de gordura, teor de proteína) e questões de infraestrutura das estradas de acesso à propriedade.

A qualidade da estrada influencia no tipo de caminhão (caminhões de grande porte precisam de estradas com boas condições para circulação) a ser utilizado na captação do leite, consequentemente passa a ser uma variável de decisão. Em Castro, foi identificado que a normativa diminuiu a especificidade locacional quando se passa a exigir o resfriamento do leite na fazenda. Sendo assim, a distância de captação cresceu, passando de uma média de $36 \mathrm{~km}$ de distância para quase $200 \mathrm{~km}$. Essa quilometragem está alinhada com o volume do leite a ser coletado.

A cooperativa também exige dos produtores um alinhamento ao protocolo de boas práticas do seu cliente DPA (Dairy Partners Américas), o principal comprador da cooperativa.

Entre os produtos industrializados pela Cooperativa, destaca-se o leite evaporado concentrado, que é fornecido para os principais processadores de leite do Brasil e representa a maior parte da produção (cerca de 70\%). 
Adicionalmente, a cooperativa tem em sua linha de produção três tipos de mercadorias que são comercializadas no varejo, sendo elas: leite UHT (ultra high temperature), achocolatado e o creme de leite.

\subsubsection{Motivações para escolhas das estruturas de governança}

O modelo de cooperação utilizado pela empresa é o de cotas de adesão. Essa norma funciona da seguinte forma: o produtor interessado em fornecer leite para a Castrolanda paga uma cota e adere a um contrato de adesão com um valor monetário, o que o torna sócio da cooperativa. Além de atender seus produtos que são ofertados no varejo, a cooperativa atende outros clientes, os consumidores que exigem leites com diferentes especificidades. Dessa forma, a empresa desenvolve estratégias de captação diferenciada, via contratos e integração vertical para atender tal demanda.

As formas de obtenção estão apresentadas na Tabela 4. Os produtores estão dentro do sistema de cooperação (com contratos indeterminados) e os demais são fornecedores devidamente cadastrados de outras empresas.

TABELA 4 - Mecanismos de Governança adotados pela Cooperativa Castrolanda / Captação de Leite

\begin{tabular}{cc}
\hline $\begin{array}{c}\text { Participação de cada Estrutura de } \\
\text { Governança }\end{array}$ & Porcentagem \\
\hline Mercado Spot & 27,0 \\
Contratos relacionais. & 15,4 \\
Contratos formais & 28,2 \\
Integração Vertical & 29,4 \\
\hline
\end{tabular}

Fonte: pesquisa de campo

Os padrões de qualidade exigidos pela cooperativa Castrolanda aos seus fornecedores estão acima das especificações da IN 62 no que tange a todos os estágios de produção. A formação de preço é feita de acordo com os dados do Centro de Estudos Aplicado em Economia (CEPEA).

Uma vez que o produtor de leite adira à cooperativa, passa a receber uma série de benefícios essenciais para o desenvolvimento da atividade leiteira, entre os quais se destacam: (i) assistência técnica ao produtor. Para os cooperados estão disponíveis treze profissionais que oferecem todo tipo de assistência necessária ao produtor; (ii) acesso às lojas que fornecem insumos necessários para realização da atividade com preços competitivos para o cooperado; (iii) acesso ao crédito para realização de benfeitorias na propriedade e melhoria da produção; e (iv) distribuição do lucro aos associados no final de cada período contábil.

O sistema de cooperados leva à eficiência dos processos produtivos e à garantia da qualidade no abastecimento de leite. Apesar de existir competição, como em qualquer setor, devido a sua reputação, aos sistemas de cotas e aos serviços oferecidos aos seus fornecedores, a Castrolanda consegue captar um volume superior de leite comparado ao de seus concorrentes.

$\mathrm{Na}$ região de Castro também existem outros laticínios operando na captação de leite que se destacam na produção nacional, sendo eles: Lácteos Brasil (LBR) e BRfoods. Há também os que se sobressaem na produção regional, tais como: Colosso, Laticínio Carolina e Qualitat, que não têm uma coordenação do sistema produtivo como o do Castrolanda.

Entre os demais problemas que influenciam a produção de leite, a instabilidade climática é a principal variável. Na região pesquisada, a queda na captação é perceptível em torno de $22 \%$ nos períodos que vão de março a abril. Nesse período, a produção gira em uma média de 14.000.000 litros/mês. Em outubro de 2015, a produção chegou a atingir 18.000.000 litros/mês (IBGE, 2015).

No SAG do leite de Castro é perceptível o elevado grau de especialização dos produtores e uma elevada homogeneidade na produção, na qual todos seguem os requisitos e especificações da IN 62. Quase a totalidade dos produtores utiliza ordenha mecânica e refrigeração do leite na fazenda.

\section{DISCUSSÃO}

De forma geral, identifica-se que as principais mudanças nas especificidades dos ativos decorrentes da IN 62 no SAG do leite estão relacionadas à especificidade de ativos físicos e dedicados, tais como: (i) uso de ordenhas mecânicas ou semimecanizadas; (ii) refrigeração do leite cru na fazenda, impondo o uso de tanques refrigerados (individual ou comunitário); (iii) investimentos para a análise mensal da qualidade do leite produzido na fazenda; (iv) participação na Rede Brasileira de Laboratórios de Controle de Qualidade do Leite (RBQL); e (v) definição de diretrizes com relação ao número aceitável de bactérias e células somáticas no leite cru. Portanto, dadas as mudanças 
institucionais, observa-se que tanto o produtor como o processador precisariam de bens próprios para a transação do produto.

No que tange ao ativo locacional, este é considerado como um fator que influencia no preço pago pelo leite. Entre as variáveis de decisão do elo processador, a localização é um fator importante para a atividade, pois o preço do produto tem uma relação com a das estradas que o caminhão passa para coletar o leite, assim como a durabilidade da relação entre os agentes.

Já a especificidade humana, por sua vez, também é considerada na atividade como algo importante para ambos os segmentos, pois é necessário ter know-how para produzir e processar, conforme a normativa prevista pelo setor.

No que se refere à especificidade temporal, esta também pode ser considerada como algo pertinente à transação do leite, visto que o laticínio tem um limite de tempo para coletar o leite produzido e o produtor precisa entregar o produto no prazo combinado. Os processadores citaram que coletam o leite a cada dois dias nos produtores, possuindo duas linhas de coleta para que o produtor tenha tempo de fazer a higienização nos animais.

Um aspecto importante desse novo regulamento era buscar maior harmonização dos padrões que variavam significativamente entre as regiões. O prazo inicial para esses ajustes foi posteriormente adiado (Instrução Normativa 07/2016) para julho de 2018 para as regiões Sul, Sudeste e Centro-Oeste e para julho de 2019 para as regiões Norte e Nordeste (Brasil, 2018a; Brasil, 2018b). ${ }^{4}$ Vale observar que os valores dos parâmetros adotados pela regulamentação estão próximos aos dos utilizados em vários países líderes na produção de leite (Groupe Agéco, 2020). No Quadro 1 estão sumarizados os principais investimentos a realizados pelos agentes do SAG do Leite para adequação às instruções normativas.

Essas modificações tiveram efeitos sobre quatro tipos de especificidade de ativos: (i) dedicado, com a necessidade de compras de equipamentos tangíveis (tanques e ordenha); (ii) temporal (perecibilidade), uma vez que o leite envasado em latão de cobre e deixado na porteira da fazenda requeria um trajeto que minimizava a probabilidade de comprometimento da qualidade no momento do processamento e a coleta era diária; (iii)

${ }^{4}$ Os parâmetros microbiológicos para o leite cru refrigerado preveem que a média geométrica trimestral da contagem bacteriana total (CBT) não deverá ultrapassar 300 mil UFC/mL para análises individuais de cada resfriador/ produtor e para a contagem de células somáticas (CCS) a média geométrica trimestral máxima ficou estabelecida em $500 \mathrm{mil}$ cels $/ \mathrm{mL}$. A periodicidade de análises de CBT e CCS é mensal. (Brasil, 2018a). locacional. Em média, a quilometragem viável para a captação de leite de produtores sem resfriamento era de 20 a $30 \mathrm{~km}$ da planta do laticínio. A localização geográfica dos fornecedores de leite cru, não resfriado, definia a seleção de fornecedores próximos aos laticínios. Com o resfriamento, o mercado relevante dos laticínios pode ser expandido (Diniz, 2019). De acordo com Camilo (2019), o processo de resfriamento e transporte em tanques refrigerados permitiu o aumento da área de coleta de leite de 20 a 119 quilômetros, até chegar a $300 \mathrm{~km}$. Por fim, (iv) especificidade humana. Os dois elos precisaram desenvolver estratégias de treinamentos das pessoas envolvidas, seja na propriedade rural (aprender a higienizar as mãos e as tetas das vacas, manusear os equipamentos, tais como as ordenhas), seja no elo processador (treinar o pessoal a realizar as pré-análises no momento da coleta e a higienizar os equipamentos). Esses treinamentos são realizados por entidades rurais locais, como a Emater em Minas Gerais e a Fundação ABC, no Paraná, e não geram custos a ambos agentes do SAG.

Observa-se que houve, por parte de produtores e processadores, um aumento nos investimentos como, por exemplo, em ativos dedicados, o que deveria levar a uma estrutura de governança mais distante de mercado, isto é, com maior número de contratos e estratégias de fidelização. Em direção contrária, o resfriamento do leite em tanque de expansão diminuiu a perecibilidade do produto, minimizando a especificidade de ativo temporal e locacional, levando a uma estratégia de governança mais próxima de mercado.

Percebe-se que a IN 62 criou mudanças que levam a resultados em direção oposta: maior especificidade de ativo dedicado, mais longe do mercado e, em casos de menor especificidade locacional e temporal, a estratégias mais próximas de mercado. A pesquisa apresentada neste artigo permite identificar o efeito líquido dessa mudança.

Há indicações de que nos dois casos apresentados as normativas levaram ao maior uso de estratégias de fidelização, como contratos, resultado que corrobora a proposição 1 e refuta a proposição 2 (apresentada na Figura 1), destacadas a seguir.

P1: Quanto maior o uso de ativos dedicados, maior o custo de transação e se espera uma estrutura de governança entre produtores e laticínios menos próxima de mercado. Assim, haveria maior probabilidade do uso de contratos visando estratégias de fidelização.

P2: Quanto menor a especificidade temporal e locacional, menor o custo de transação e se espera uma estrutura de governança mais próxima do mercado. 
Assim, haveria uma menor probabilidade do uso de contratos visando estratégias de fidelização.

É importante notar que observamos o efeito líquido, ou seja, o efeito da proposição 1 pode ter sido mais forte que o efeito da proposição 2. Outro ponto, considerado mais importante, é que as mudanças locacional e temporal implicaram o aumento do mercado relevante para os laticínios. Os produtores de leite, que antes ficavam limitados a comercializar com o laticínio da região, passaram a ter a oportunidade de comercializar com outros laticínios, particularmente em períodos de maximização da demanda (ou escassez da oferta em outras regiões). Esse fato propicia maior poder de barganha aos produtores. A maior concorrência entre os derivados do leite reflete-se na criação de instrumentos de fidelização do produtor.

De Lima, Perez, \& Chaves (2017) constataram que, em geral, os laticínios no Brasil operam abaixo da capacidade instalada, com capacidade ociosa entre $20 \%$ e $30 \%$ da total instalada. O conjunto de investimento em ativos (caminhão com tanque resfriado, tanque de armazenamento) amplia as estratégias dos laticínios em captar leite em regiões distantes da sua planta, ampliando o ambiente concorrencial dos demais laticínios. A maior concorrência na captação do leite reflete-se na criação de instrumentos de fidelização com produtor, ou seja, contratos relacionais que garantam o abastecimento dos laticínios.

No caso da Cooperativa Castrolanda, faz parte da estratégia da empresa ter uma relação mais estreita com produtores tendo em vista as exigências dos consumidores, que envolvem subprodutos diferenciados do leite cru. Essa relação mais estreita faz com que a empresa atue de maneira mais próxima aos produtores diante do cenário apresentado, o que pode ser evidenciado pelo fato de que mais de $60 \%$ do fornecimento é via relações formais e relacionais. No caso dos Laticínios Porto Alegre, as relações por mercado spot correspondem a quase $45 \%$ das compras de leite. Já os contratos relacionais, sem contrato, representam em torno de 54\%. Resta saber se os Laticínios Porto Alegre irão aumentar a porcentagem de fornecimento a partir de relações mais formais e com maior controle com seus fornecedores.

\section{CONCLUSÃO}

Neste artigo buscou-se entender a dinâmica das relações (estrutura de governança) entre os dois importantes elos da cadeia produtiva do leite: os produtores rurais e os laticínios. As unidades de análise foram as mudanças institucionais, em específico, a IN 62. Com base nesse problema de pesquisa, foram elaboradoras duas proposições de pesquisa.

No caso da primeira proposição, "quanto maior o uso de ativos dedicados, maior o custo de transação e se espera uma estrutura de governança entre produtores e laticínios menos próxima de mercado, ou seja, é maior o uso de contratos, visando estratégias de fidelização". Houve aumento da especificidade de ativos, do ponto de vista de o produtor realizar investimentos principalmente para a refrigeração do leite na propriedade. Por outro lado, ao diminuir a perecibilidade do produto, os fornecedores passam a ter um escopo maior de compradores, localizados mais distantes da propriedade. Ou seja, de acordo com a ECT, aumentou-se o poder de barganha dos produtores.

Sob o ponto de vista do laticínio, aumentou a gama de fornecedores, mas também aumentou a concorrência para compra do leite. A questão especificamente das mudanças em termos de contrato pode ser identificada mais claramente no caso da Cooperativa Castrolanda. No entanto, esse comportamento no qual as relações são mais formais e relacionais também pode ser influenciado pelas características dos clientes da Cooperativa, os quais demandam um produto mais diferenciado. Há indicações de que, no caso da Cooperativa, mesmo antes da implantação da IN 62 as cooperativas e seus associados adotavam as práticas previstas na legislação.

No caso dos Laticínios Porto Alegre, antes da IN as transações eram mais comumente realizadas via mercado e integração vertical. Com as mudanças institucionais, o laticínio passou a utilizar contratos relacionais.

Observou-se um efeito líquido da diminuição da especificidade temporal e locacional. Em tese, a lógica da aquisição da matéria-prima (no caso, o leite cru) tenderia ser a negociação via mercado, pois o produtor tem uma oferta maior de comprador, mas esse ponto não foi observado nos resultados da pesquisa. Sob o ponto de vista da ECT, foram observados o desenho de novos arranjos contratuais, por parte do elo processador em busca de fidelização, e a garantia de entrega do leite. Nesse sentido, a segunda preposição expressa por "quanto menor a especificidade temporal e locacional, menor o custo de transação e se espera uma estrutura de governança mais próxima do mercado, ou seja, é menor o uso de contratos, visando estratégias de fidelização", foi refutada.

Identifica-se, portanto, que nos casos estudados, outro efeito da IN foi a diminuição das especificidades temporal e locacional dos ativos o que causou um aumento na competição pelo produto e ocasionou relações mais formais entre os produtores de leite e a empresa 
processadora, devido ao aumento da concorrência no mercado relevante. No caso da Castrolanda, as relações não apresentaram mudanças, pois os agentes já adotavam as práticas definidas pela normativa e as relações entre os agentes também previam fidelização dos produtores. No caso do Porto Alegre, a IN teve um efeito importante, já que não se adotava a prática de refrigeração e o resultado mais importante foi o aumento da concorrência entre os laticínios.

No que se refere às limitações do estudo, um ponto a destacar é o fato de esse resultado ser conjuntural, uma vez que se observa um aumento da demanda, implicando maior disputa entre as empresas processadoras. Adicionalmente, a pesquisa enfocou apenas duas regiões que, apesar de importantes, não representam a totalidade da produção nacional de leite.

Em termos de implicações teóricas, o artigo traz insights importantes para a complementariedade da análise dos mercados e das transações para analisar os resultados empíricos encontrados. Também é oportuno constatar os efeitos das mudanças institucionais sob a perspectiva dos laticínios e dos produtores, mostrando diferentes efeitos e abrindo possibilidade para nortear políticas públicas que levem em conta as relações entre os agentes e os efeitos das mudanças institucionais sob diferentes enfoques. Por fim, é recomendável a realização de trabalhos com uma abordagem longitudinal para entender de maneira mais ampla os efeitos das mudanças institucionais sob os agentes econômicos da cadeia do leite.

\section{AGRADECIMENTOS}

Agradecemos o apoio financeiro do Center for Organization Studies - (CORS/FEA/USP), do International Food Policy Research Institute (IFPRI) e do CNPq.

\section{CONFLITO DE INTERESSES}

Não houve conflitos de interesse no assunto ou nos materiais discutidos neste manuscrito.

\section{REFERÊNCIAS}

Azevedo, P. F. (1997). Comercialização de produtos agroindustriais. In A. L. Silva, J. C. Toledo, J. F. D. Nantes, L. F. Paulillo, M. R. P. A. Alves, P. F. Azevedo, P. Stahlberg Filho, R. L. Sproesser, \& S. Bialoskorski Neto (Orgs.), Gestão agroindustrial (pp. 49-82). Atlas.

Barbetta, P. A. (2003). Estatística Aplicada às Ciências Sociais. $1^{\text {a }}$. Ed. Santa Catarina: Editora da UFSC.
Brasil. (2011). Instrução Normativa no 62, de 29 de dezembro de 2011. Aprovar o Regulamento Técnico de Produção, Identidade e Qualidade do Leite tipo A, o Regulamento Técnico de Identidade e Qualidade de Leite Cru Refrigerado, o Regulamento Técnico de Identidade e Qualidade de Leite Pasteurizado e o Regulamento Técnico da Coleta de Leite Cru Refrigerado e seu Transporte a Granel, em conformidade com os Anexos desta Instrução Normativa. Recuperado em 21 de Agosto de 2020, de https://www.normasbrasil.com.br/norma/instrucaonormativa-62-2011_78285.htm

(2018a). Instrução Normativa $n^{\circ} 76$, de 26 de novembro de 2018. Aprova os Regulamentos Técnicos que fixam a identidade e as características de qualidade que devem apresentar o leite cru refrigerado, o leite pasteurizado e o leite pasteurizado tipo A. Recuperado em 21 de Agosto de 2020, de http://www.in.gov.br/materia/-/asset_publisher/ Kujrw0TZC2Mb/content/id/52750137/do1-2018-1130-instrucao-normativa-n-76-de-26-de-novembrode-2018-52749894IN\%2076

(2018b). Instrução Normativa $n^{\circ} 77$, de 26 de novembro de 2018. Estabelece os critérios e procedimentos para a produção, acondicionamento, conservação, transporte, seleção e recepção do leite cru em estabelecimentos registrados no serviço de inspeção oficial. Recuperado em 21 de Agosto de 2020,de http:// www.in.gov.br/materia/-/asset_publisher/Kujrw0TZC2Mb/ content/id/52750141/do1-2018-11-30-instrucao-normativan-77-de-26-de-novembro-de-2018-52749887

Camilo, P. J. (2019). A reestruturação dos sistemas de transporte de lácteos sob a perspectiva das novas estratégias mercadológicas da indústria de laticínios no estado do Paraná. GeoTextos, 15(2), 109-122.

Coase, R. H. (1937). The nature of the firm. Economica, New Series, 4(16), 386-405.

Defante, L., Damasceno, J. C., Bánkuti, F. I., \& Ramos, C. E. C. D. O. (2019). Typology of dairy production systems that meet Brazilian standards for milk quality. Revista Brasileira de Zootecnia, 48.

De Lima, L. P., Perez, R., \& Chaves, J. B. P. (2017). A indústria de laticínios no brasil-um estudo exploratório. Boletim do Centro de Pesquisa de Processamento de Alimentos, 35(1). 
Diniz, V. M. F. (2019). Análise das estruturas de governança de laticínios e produtores no Oeste do Paraná sob a ótica dos custos de transação e formas plurais [Dissertação de Mestrado, Universidade Estadual do Oeste do Paraná]. http://tede.unioeste.br/handle/ tede/4365

Farina, E. M. M. Q., Azevedo, P. F. de, \& Saes, M. S. M. (1997). Competitividade: mercado, estado e organizações. São Paulo: Singular.

Food and Agriculture Organization. (2018). FAOSTAT database. Recuperado em 22 dezembro, 2020, de www. faostat.fao.org

FAO, IFAD, UNICEF, WFP \& WHO, (2018). The State of Food Security and Nutrition in the World 2018. Building climate resilience for food security and nutrition. Rome: FAO

Gerosa, S., \& Skoet, J. (2013). Milk availability: current production and demand and medium-term outlook. In Muehlhoff, E., Bennett, A., \& McMahon, D. (eds.). Milk and dairy products in human nutrition (pp. 11-14). Food and Agriculture Organization of the United Nations (FAO).

Gil, A. C. (2019). Métodos e Técnicas de Pesquisa Social. (7 . Ed). São Paulo: Atlas.

Groupe Agéco. (2020). Évolution des recettes laitières et des recettes monétaires totales en agriculture, par province. Recuperado em 15 de Setembro de 2020, de http://groupeageco.ca/fr/pdf/stat/QCM1.pdf

Instituto Brasileiro de Geografia e Estatística (2013). Síntese dos Indicadores Sociais: Uma Análise das Condições de Vida da População Brasileira 2013. Rio de Janeiro, 2013. Recuperado em: 20 de dezembro de 2019 em http:/www.ibge.gov.br/.

Instituto Brasileiro de Geografia e Estatística. (2015). Mudança na cobertura e uso da terra 2000-2010-2012. Recuperado em: 20 de dezembro de 2016 em http://www. ibge.gov.br/.

Instituto Brasileiro de Geografia e Estatística (2018). Produção da pecuária municipal. Disponível em: < http://biblioteca.ibge.gov.br/visualizacao/periodicos/84/ ppm_2015_v43_br.pdf $>$. Acesso em: 10 dez. 2019.
Januário, É. C. (2014). Mudanças institucionais e as relações entre produtores rurais e o segmento processador de leite no Brasil [Dissertação de Mestrado, Universidade de São Paulo]. https:/teses.usp.br/teses/ disponiveis/12/12139/tde-24112014-171233/en.php

Joskow, P. L. (1995). The New Institutional Economics: alternative approaches. Journal of Institutional and Theoretical Economics, 151(1), 248-259.

Kischner, P., Brum, A. L., Muenchen, J. V. \& Basso, D. (2019). A cadeia produtiva do leite na Região Noroeste do RS: estudo de caso do município de Ijuí. Brazilian Journal of Development, 5(9), 15162-15176.

Klein, B., Crawford, R., \& Alchian, A. (2012). Vertical integration, appropriable rents, and the competitive contracting process. The Journal of Law and Economics, 21(2), 297-326.

Klein, Benjamin.(2000) Fisher-General Motors and the nature of the firm. Journal of Law and Economics. Chicago: University of Chicago Press, v. 43, issue 1, p. 105-141.

Mesquita, L. A. F., Pozzebon, M., \& Petrini, M. (2020). Construindo espaços de interação social a partir de relações e práticas de trabalho compartilhado. Revista de Administração Contemporânea, 24(2), 181-196.

Miles, M. B., Huberman, A. M., \& Saldana, J. (2014). Qualitative data analysis: A methods sourcebook. (4 $\left.{ }^{\mathrm{a}} \mathrm{Ed}\right)$. SAGE Publications.

Milgrom, P.; Roberts, J. (1992). Economics, organization and management. $1^{\mathrm{a}}$ ed. Prentice-Hall.

Mondelli, M., \& Zylbersztajn, D. (2008). Determinantes dos arranjos contratuais: o caso da transação produtorprocessador de carne bovina no Uruguai. Revista de Economia e Sociologia Rural, 46(3), 831-868.

Muris, T. J., Scheffman, D. T., \& Spiller, P. T. (1992). Strategy and transaction costs: the organization of distribution in the carbonated soft drink industry. Journal of Economics and Management Strategy, 1(1), 83-128.

North, D. C. (1990). Institutions, Institutional change and economic performance. Cambridge University Press. 
Oliveira, L. F. T., \& Silva, S. P. (2012). Mudanças institucionais e produção familiar na cadeia produtiva do leite no oeste catarinense. Revista de Economia e Sociologia Rural, 50(4), 705-720.

Perry, M. K. (1989). Vertical integration: Determinants and effects. In R. Schmalensee, M. Armstrong, R. D. Willig, R. H. Porter, \& M. A. Armstrong (Eds.). Handbook of industrial organization (1st ed., pp. 183-255). NorthHolland.

Reis, R. P. Fundamentos de economia aplicada. (1.a Ed) Lavras: UFLA/FAEPE, 2007.

Rocha, D.R. \& Carvalho, G.R. Produção Brasileira de leite: uma análise conjuntural. (2018).. In Martins, P.C, Zoccal, R., Rentero, N. Albuquerque, A (Eds.). Anuário leite 2018: Indicadores, tendências e oportunidades para quem vive no setor leiteiro, $1^{\mathrm{a}} \mathrm{ed}$. EMBRAPA.

Williamson, O. E. (1973a). Markets and hierarchies, some elementary considerations. American Economic Review, 63(2), 316-256.
. (1973b). Organizational forms and internal efficiency markets and hierarchies: some elementary considerations. American Economic Review, 63(2), 316325 .

. (1985). The economic institutions of capitalism.

New York FreePress.

. (1987). Transaction cost economics: the comparative contracting perspective. Journal of Economic Behavor \& Organization, 8(4), 617-625.

(1991). Comparative economic organization: the analysis of discrete structural alternatives. Administrative Science Quarterly, 36(2), 269-296.

Zylbersztajn, D., \& Farina, E. M. M. Q. (1999). Strictly coordinated food-systems: exploring the limits of the Coasian firm. International Food and Agribusiness Management Review, 2(2), 249-265.

Yin, R. K. 2014. Case Study Research: Design and Methods (5th ed.). Sage Publication. 